\title{
Vegetable derived antioxidant and vitamin D: effects on oxidative stress and bone mineral metabolism of aged patients with renal disease
}

\author{
Francesco Carluccio*1, Macello Lenucci ${ }^{1}$, Gabriella Piro', Werner Siems ${ }^{3}$ and Josè Luño \\ ${ }^{1}$ Department of Biological and Environmental Sciences and Technologies, University of Salento, \\ Lecce, Italy; ${ }^{2}$ Hospital General Universitario Gregorio Marañon, University Complutense of \\ Madrid, Madrid, Spain; ${ }^{3}$ Kortex-Med Institute, Institute for Physical Medicine and \\ Rehabilitation, Bad Harzburg, Germany
}

*Corresponding author: Francesco Carluccio, MD, PhD, Department of Biological and Environmental Sciences and Technologies, University of Salento, Lecce, Italy

Submission Date: May 31, 2016, Accepted Date: June 22, 2016, Publication Date: June 29, 2016

\begin{abstract}
Background: Aging and chronic kidney disease (CKD) are associated with bone mineral metabolism disorders, in addition to disarrangement of trabeculae structure and bone architecture. Increased alkaline phosphatase (ALP) and parathyroid hormone (PTH) have been related with abnormal bone turn over. Lycopene, a plant derived micronutrient, has strong quenching and free radical scavenging attitude.
\end{abstract}

Objectives: This study aimed to evaluate the effects of lycopene and calcifediol (25 OH D3) based Integrated Medicine on ALP, PTH and oxidative stress.

Methods: In octogenarians, nonagenarians and centenarians with chronic kidney disease (GFR :45 $\pm 10,4 \mathrm{ml} / \mathrm{min} / 1,73 \mathrm{~m}^{2}$ ), vitamin D deficiency and abnormal ALP, PTH blood values, the effects of daily lycopene supplementation on blood oxysterols and on 4-hydroxy-2,3-transnonenal (4-HNE) as markers of oxidative stress were evaluated. The effects of calcifediol administration together with daily lycopene supplementation on PTH and ALP blood concentrations were also investigated.

Results: Daily lycopene supplementation induced a reduction of oxysterols ( $\alpha$-triol: $0.40 \pm 0.07$ $\mu \mathrm{g} / \mathrm{L} v s 0.32 \pm 0,04 \mu \mathrm{g} / \mathrm{L}$ and $\beta$-epoxi cholesterol: $5.3 \pm 1.3 \mu \mathrm{g} / \mathrm{L} v s 3.7 \pm 0.6 \mu \mathrm{g} / \mathrm{L})$ but not of 4-HNE $(0.27 \pm 0.18 \mathrm{nmol} / \mathrm{L}$ vs $0.25 \pm 0.20 \mathrm{nmol} / \mathrm{L})$. Vitamin D added to lycopene for two weeks decreased the blood values of ALP $(106 \pm 40 \mathrm{U} / \mathrm{L}$ vs $69 \pm 19 \mathrm{U} / \mathrm{L})$ and PTH $(108 \pm 42$ $\mathrm{pg} / \mathrm{ml}$ vs $66 \pm 21 \mathrm{pg} / \mathrm{ml})$.

Conclusion: Tomato derived lycopene, with daily supplements, decreased cholesterol oxidation products. Calcifediol and vegetable derived antioxidant daily supplementations were associated to normalization of ALP and PTH. 
Keywords: oxysterols; 4-hydroxynonenal; lycopene; alkaline phosphatase; parathyroid hormone; chronic kidney disease (CKD)

\section{INTRODUCTION}

By 2060, the proportion of European population aged 65 and over is predicted to increase from $17.4 \%$ to $30 \%$ and the demographic old-age dependency ratio (people aged 65 relative to those aged 15-64) is projected from $27.8 \%$ to $50.1 \%$ [1]. A proportional rise in chronic degenerative diseases related to aging, cardiovascular, muscular, skeletal and kidney diseases, in addition to diabetes and cancer and the increasing demand of long-term care are also predicted.

Oxidative stress, defined as an imbalance between antioxidants and prooxidants in favor of oxidants, has a fundamental aetiopathogenetic role [2]. Increased activity of reactive oxygen species and/or antioxidants depletion have been involved in aging related diseases and imbalanced bone remodeling which characterizes osteoporosis [3]. It has been proposed that oxidative stress negatively influences bone mass and bone structure via the activation of the oxidative stress-responsive transcription factor NF-kB [4]. In the Framingham Osteoporosis Study, a higher intake of lycopene, a phytonutrient of the carotenoids family, in men and women was positively associated with 4 years amelioration in bone mineral density (BMD) at lumbar vertebrae, in addition to lower risk for hip and non-vertebral fractures [5].

Carotenoids form one of the most important classes of natural pigments. Both animals and human beings are unable to synthesize them, instead requiring a dietary intake [6]. Carotenoids are typically associated with cell membranes; being highly lipophilic molecules, they are located exclusively within the hydrophobic core of membranes bilayer. Besides their function as antioxidants, carotenoids are believed to be involved in many biological functions and they could markedly influence the properties of the membranes (rigidity, thickness, mechanical strength, fluidity and permeability), signal transduction [7, 8] and induction of cell cycle arrest [9, 10]. In epidemiological studies, higher levels of serums carotenoids were associated with a lower risk of cardiovascular diseases [11], cancer [12, 13, 14], atherosclerosis [15] and osteoporosis [5]. Vitamin D plays a crucial role in the maintenance of calcium and physiological bone turnover. Alterations in bone metabolism often occur when there is chronic vitamin D deficiency, increasing in parathyroid gland activity and chronic renal failure [16]. The estimated requirement of vitamin $\mathrm{D}$ is about $10 \mu \mathrm{gr} /$ day in healthy adults and the daily endogenous production of 1-25 $(\mathrm{OH}) 2 \mathrm{D} 3$ varies from 0.5 to $2 \mu \mathrm{gr} /$ day while that of $25(\mathrm{OH}) \mathrm{D} 3$ varies from 3 to $12 \mu \mathrm{gr} /$ day [17].

However, a widespread basal deficiency of vitamin D also among the general population has been detected, particularly in individuals over the age of fifty [18].

In this study, we hypothesized that an integrated medicine curative approach might have beneficial effects to aged persons with CKD exposed to oxidative stress and that daily supplementation of calcifediol and lycopene might counterbalance the free radical and CKD related pathological consequences on bone metabolism.

\section{SUBJECTS AND METHODS}

\section{Subjects}

Five octogenarians, three women, two men (age $82.6 \pm 2.5$ years), two women nonagenarians (age 91 years, 93 years) and three centenarians, one man, two women (age 102.3 \pm 2 years) were selected and had provided informed consent. They were affected by different chronic degenerative diseases and were under specific pharmacological treatment which remained 
unchanged, as have remained unchanged eating habits and lifestyle. In all centenarians, nonagenarians, and in two of five octogenarians, insufficient vitamin D blood values were found. Three octogenarians (two women, one man) had vitamin D blood values within the normal range and were excluded from the study. Estimated glomerular filtration rate (eGFR) of the remaining seven persons who have continued the study was $45 \pm 10.4 \mathrm{ml} / \mathrm{min} / 1.73 \mathrm{~m}^{2}$.

\section{Methods}

Glomerular filtration rate has been calculated by Cochroft Gault equation. Vitamin D and parathyroid hormone were assessed by standardized automated method of chemiluminescence immunoassay. Alkaline phosphatase was measured by automated analyzer unit Synchron LXi 725 (Sinchron Access Clinical Systems).

Oxysterols and 4-HNE were measured as markers of oxidative stress. In particular, by HPLC analysis the concentration of 4-hydroxy-2, 3-trans-nonenal; while the concentrations of two oxysterols: cholestane-3 $\beta, 5 \alpha, 6 \beta$-triol and $5 \beta-6 \beta$ epoxy-cholesterol were measured after extraction, derivation and gas chromatographic separation. The concentrations of these oxidative and carbonyl stress markers were assayed before and after dietary supplementation with lycopene, $10 \mathrm{mg} / \mathrm{day}$, contained in tablet with $100 \mathrm{mg}$ of tomato powdered of which $10 \mathrm{mg}$ of lycopene. One participant had chosen to drink $100 \mathrm{mg} /$ day of tomato juice, instead of tablets containing $10 \mathrm{mg}$ of lycopene (according to USDA National Nutrient Data Base [19]). Lycopene daily supplementation was continued for 6 weeks. Subsequently, after dosage of the basal blood concentration of 25-OHD3 (calcifediol), started supplementation with calcifediol, at a dose of 50 micrograms / day for two weeks, preceded and followed by dosing of blood alkaline phosphatase, parathyroid hormone and serum calcium and phosphorus.

Data are presented as mean \pm SD (Standard Deviation). Statistical analysis has been performed using "T" Student Test. Statistical significance was set at $\mathrm{P}<0.05$.

\section{RESULTS}

The quantitative analysis of oxysterols and 4-HNE, carried out before the beginning of the daily dietary supplementation with lycopene in 7 participants, revealed the existence of a condition of oxidative stress. See Figure 1.

The average value of this byproduct of lipid peroxidation, 4-hydroxy-2,3-trans-nonenal (4$\mathrm{HNE}$ ), was found to be $0.27 \pm 0.18 \mathrm{nmol} / \mathrm{L}$. Pathological concentrations of oxysterols were also revealed. In particular, there was an increase in the "baseline condition" of the values of cholesterol oxidation products, $\alpha$-triol and $\beta$-epoxy cholesterol whose average and relative standard deviations were $0.40 \pm 0.07 \mu \mathrm{g} / \mathrm{L}$ and $5.3 \pm 1.3 \mu \mathrm{g} / \mathrm{L}$ for $\alpha$ - triol and $\beta$-epoxy cholesterol respectively.

The analysis of the same oxidative stress parameters in the group of octogenarians, nonagenarians and centenarians repeated after six weeks of dietary supplementation with lycopene showed statistically different variations amongst cholesterol oxidation products, in particular $\alpha$-triol $0.40 \pm 0.07 \mathrm{mg} / \mathrm{L}$ vs $0.32 \pm 0.04 \mathrm{~g} / \mathrm{L},(\mathrm{p}<0.01)$ and $\beta$-epoxi cholesterol $5.3 \pm$ $1.3 \mu \mathrm{g} / \mathrm{L} v s 3.7 \pm 0.6 \mu \mathrm{g} / \mathrm{L},(\mathrm{p}<0.01)$, while concentrations of 4-HNE remained substantially unchanged $(0.27 \pm 0.18 \mathrm{nmol} / \mathrm{L}$ vs $0.25 \pm 0.20 \mathrm{nmol} / \mathrm{L})$. See Figure 1 .

Statistical differences of alkaline phosphatase and parathyroid hormone blood basal values "pre" vs "post supplementation with lycopene and calcifediol were discovered, while no statistical significances were observed in calcemia and in phosphatemia. In particular, the blood concentrations of the enzyme ALP, found still elevated after the intake of lycopene alone, were reduced to values within the normal range related to age (106 $\pm 40 \mathrm{U} / \mathrm{L}$ vs $69 \pm 19 \mathrm{U} / \mathrm{L})$ after 
supplementation with lycopene and vitamin D. A similar fluctuation, with statistical significance, was highlighted by the analysis of parathyroid hormone blood values $(108 \pm 42 \mathrm{pg} / \mathrm{ml} v s 66 \pm 21$ $\mathrm{pg} / \mathrm{ml} ; \mathrm{p}<0.05$ ). [Figure 2, Figure 3].

\begin{tabular}{|c|c|c|c|}
\hline \multicolumn{4}{|c|}{$\begin{array}{l}\text { oxidative stress parameters before and after } \\
\text { lycopene diet supplement }\end{array}$} \\
\hline \multicolumn{2}{|c|}{ Before lycopene diet suppl. } & \multicolumn{2}{|c|}{ after lycopene diet suppl. } \\
\hline 4-HNE & $0,27 \pm 0,18 \mathrm{nmol} / \mathrm{L}$ & 4-HNE & $5 \pm 0,20 \mathrm{nmol} / \mathrm{L}$ \\
\hline \multicolumn{2}{|c|}{ Oxysterols } & \multicolumn{2}{|c|}{ Oxysterols } \\
\hline $\begin{array}{l}\beta \text {-epoxi } \\
\alpha \text {-triol }\end{array}$ & $\begin{array}{l}5,3 \pm 1,3 \mu \mathrm{g} / \mathrm{L} \\
0,40 \pm 0,07 \mu \mathrm{g} / \mathrm{L}\end{array}$ & $\begin{array}{l}\beta \text {-epoxi } \\
\alpha \text {-triol }\end{array}$ & $\begin{array}{l}3,7 \pm 0,6 \mu \mathrm{g} / \mathrm{L} \\
0,32 \pm 0,04 \mu \mathrm{g} / \mathrm{L}\end{array}$ \\
\hline
\end{tabular}

Figure.1. Parameters of oxidative stress assessed in 7 participants before and after lycopene diet supplementation

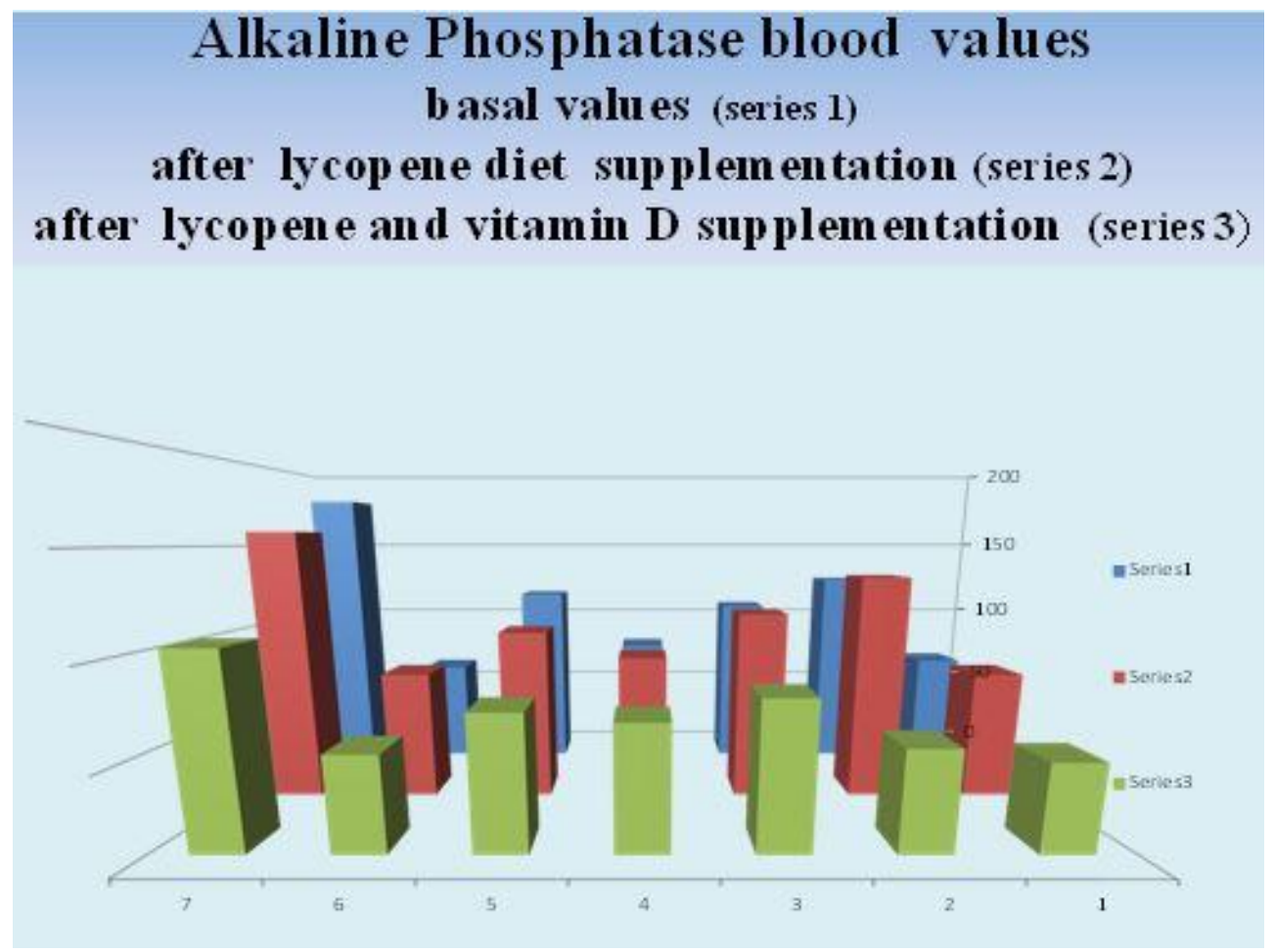

Figure 2. Series 1 represent the baseline, pre-supplementation with lycopene; series 2 represent the values after 6 weeks of supplementation with lycopene (10 mg / day); series 3 represent the values after 2 weeks of supplementation with lycopene (10 mg / day) and vitamin D (calcifediol: $50 \mathrm{mcg} /$ day). Values series 1 vs 3 ( $p<0.01$ ); values series 1 vs 2 ( $>0.05 \mathrm{~ns}$ ). [7 participants; blood levels of ALP measured in each participant are shown numbered from 1 to 7 ; values of ALP expressed in U / L] 


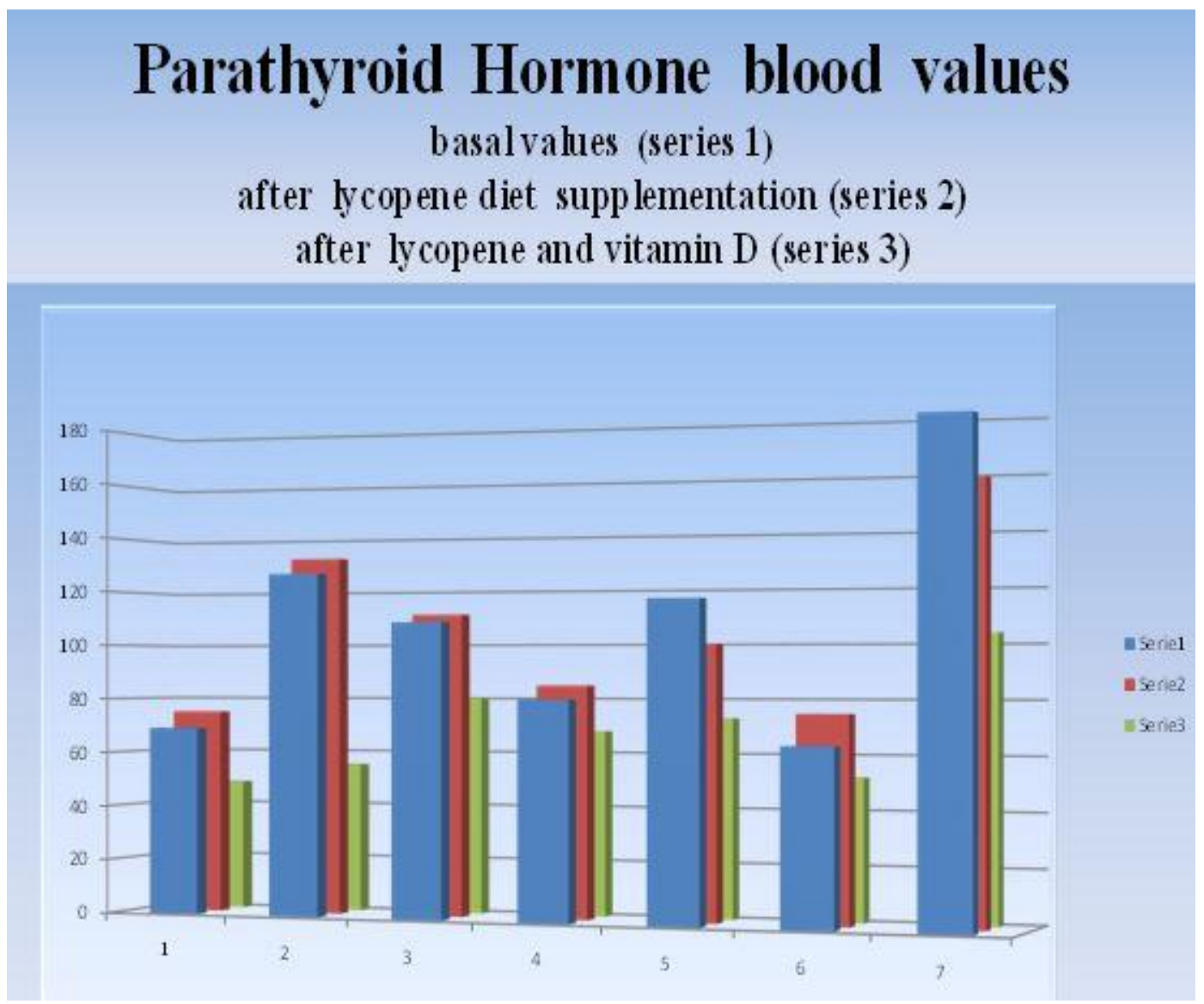

Figure 3. Basal blood values in 7 participants (series 1); after lycopene diet supplementation (10 $\mathrm{mg} /$ day) for 6 weeks (series 2) and after lycopene (10 mg/day) and vitamin D administration (50 $\mathrm{mcg} / \mathrm{die}$ ) for 2 weeks (series 3). Parathyroid Hormone is expressed in $\mathrm{pg} / \mathrm{ml}$ (blood normal values $10-70 \mathrm{pg} / \mathrm{ml}$ ) [series 1 vs series $3 \mathrm{p}<0,05$ ]

\section{DISCUSSION}

Evidence derived from observational studies and relating to the dietary content of antioxidants from plant have supported the hypothesis of a protective role of carotenoids in diet against several chronic degenerative diseases [20, 21, 22, 11].

Lycopene is an acyclic isomer of $\beta$-carotene and highly insatured hydrocarbon with 11 conjugated and two non-conjugated double bonds. In human plasma, lycopene is present as a mixture of isomers of which approximately $50 \%$ is in the $\mathrm{Z}$ form [23]. Lycopene is one of the most powerful vegetable derived antioxidants in the diet. At least 700 carotenoids have been described, however, of the 700 members, about 40 are commonly present in the diet and among them, only 20 have been identified in human tissue and blood including mainly (at least up to $90 \%$ of total identified carotenoids) $\beta$-carotene, $\alpha$-carotene, lycopene, lutein and $\beta$-cryptoxanthin $[24,25]$.

Animals and humans are unable to synthesize carotenoids de novo; therefore food intake constitutes the only source. Even if the lycopene structure is substantially stable, it may undergo photodegeneration, thermodegradation and oxidative degradation. (5Z)- lycopene is the most 
stable isomeric form followed by all-E, 9-, 13-, 15-, 7- and 11-(Z)- isomers. It is also the isomer with the highest antioxidant capacity [26].

Lycopene has a high ability to "quench" singlet oxygen, double compared to $\beta$-carotene and ten times greater than that of $\alpha$-tocopherol. Due to its lipophilic properties, it is concentrated in serum low and very low density lipoprotein (LDL and VLDL). Lycopene is also concentrated in adrenal glands, testes, liver and prostate and is, within this gland, the most represented carotenoid [25].

In the context of lipid metabolism, lycopene acts as hypocholesterolemic agent, with inhibitory effects on HMG-CoA (3-hydroxy-3-methylglutaryl-coenzyme A) reductase [27]. The HMG-CoA inhibition is accompanied by a reduction in intracellular cholesterol levels, which constitutes the bases of lycopene hypocholesterolemic effect.

Other functions operated by lycopene are a set of biomolecular phenomena that contrast in human macrophages the pro-inflammatory cascade induced by cholesterol oxidation products known as oxysterols [28].

The conjugated double bonds of lycopene play an important role in energy transfer reactions and in its quenching ability [29].

In our investigation, the reduction of cholesterol oxidation products, oxysterols, may be the result of lycopene hypocholesterolemic effect added to its high antioxidant activity. It has been reported that reactive oxygen species also take part in osteoclast differentiation and in their hyperactivity, which lead to osteopenia and osteoporosis.

Osteoporosis is considered the result of an imbalance in bone remodeling by inadequate osteoblasts activity and / or excessive osteoclasts activity, the cells responsible for bone resorption [30]. Calcitriol and PTH are closely related hormones in the context of bone physiology and pathophysiology, in calcium homeostasis and in bone mineralization. Alterations in bone metabolism often occur associated to chronic vitamin D deficiency and increased blood concentrations of parathyroid hormone. PTH directly stimulates the synthesis of calcitriol, by regulating the activity of the renal enzyme 1- $\alpha$ hydroxylase [31]. Parathyroid hormone in the same condition also stimulates bone reabsorption causing increased bone turnover by means of increased osteoclasts activity.

Calcitriol is the most biologically active form of the "hormone vitamin D "characterized by higher affinity for the vitamin D receptor (VDR), compared with $25(\mathrm{OH}) \mathrm{D} 3$ affinity and has an half life of 4-6 hours [18]. Currently it is estimated that at least 3,000 binding sites for the VDR are present within the human genome, indicating about $3 \%$ of the entire genome that directly or indirectly are responsive to activation of the VDR [32].

The form $25(\mathrm{OH}) \mathrm{D} 3$ is widely accepted as representative of biologically active circulating forms concentration and of biosynthetic activity. In last years, the assays of $25(\mathrm{OH})$ D3 blood concentrations have been increased [31]. The extensive assessment of blood concentrations of 25 $(\mathrm{OH})$ D3 made it possible to detect a widespread basal deficiency of vitamin D among the general population, especially in individuals over the age of fifty [18].

Taking in account the results of this study, we could speculate that in aged CKD patients with insufficient vitamin D blood values and parathyroid gland disfunction, lycopene, because of its high antioxidant capacity, could exert synergic effect with vitamin D to counterbalance 
osteoclasts differentiation as their oxidative stress and PTH induced hyperactivity and bone reabsorption.

\section{CONCLUSION}

The main limits of this study involved the small number of participants and to the relatively brief time of lycopene and vitamin D supplementation. However, it suggests the effectiveness of lycopene to contrast free radical formed cholesterol oxidation products in aged patients with CKD and the protective role of vitamin D together with lycopene against CKD and age related anomalous ALP and PTH values. This study also suggests a preventive and protective role of an integrated medicine curative approach based on vegetable antioxidant in CKD. In depth and longer studies will be necessary in order to evaluate the long term benefits, for example against the progression of CKD in the elderly, of dietary lycopene supplementation. Further studies are also needed to evaluate the preventive and therapeutic role of integrated medicine based on vegetable derived antioxidant and vitamin D in imbalanced bone mineral metabolism and bone turn-over.

Financial support: none

Conflicts of interests: The authors declare that there is no conflict of interests

\section{REFERENCES}

1. European Commission Directorate General for Economics and Financial Affairs Brussels, Belgium. The 2015 Ageing Report: Economic and budgetary projection for the 28 EU Member States (2013-2060). European Economy 3/2015: 1-2; 115-120 http://europa.eu/epc/pdf/ageing_report_2015_en.pdf

2. Negre-Salvayre A, Coatrieux C, Ingueneau C and Salvayre R. Advanced lipid peroxidation end products in oxidative damage to proteins. Potential role in diseases and therapeutic prospects for the inhibitors. British Journal of Pharmacology 2008 153, 6-20

3. Basu S, Michaelsson K, Olofsson H, Johansson S, Melhus H. Association between axiddative stress and bone mineral density. Biochem. Biophys Res.Common. 2001; 288: 275-279.

4. Schreck R, Rieber P, Baeuerle P A. Reactive oxygen intermediates as apparently widely used messengers in the activation of the NF-kappa B transcription factor and HIV-1. EMBO J. 1991 10(8): 2247-2258

5. Sahni S, Hannan M T, Blumberg J, Cupples L A, Kiel D P, Tucker L K. Inverse association of carotenoid intakes with 4-y change in bone mineral density in elderly men and women: the Framingham Osteoporosis Study. Am J Clin Nutr 2009 89:41624

6. Paul DF and Peter MB. The biosynthesis and nutritional uses of carotenoids. Progress in Lipid Research 200443 (3): 228-265. 
7. Britton G. Structure and properties of carotenoids in relation to function. FASEB J. 1995 9:1551-1558.

8. Gruszecki, W.I.; Strzałka, K. Carotenoids as moldulators of lipid membrane physical properties. Biochim. Biophys. Acta 2005 1740: 108-115

9. Krinsky NI. Actions of carotenoids in biological systems. Annu Rev Nutr 1993 13:561- 87.

10. Palozza P, Parrone N, Simone R, Catalano A. Role of lycopene in the control of ROSmediated cell growth: implications in cancer prevention. Curr Med Chem. 2011 18(12):1846-60.

11. Sesso, H.D.; Buring, J.E.; Norkus, E.P.; Gaziano, J.M. Plasma lycopene, other carotenoids, and retinol and the risk of cardiovascular disease in women. Am. J. Clin. Nutr. 2004 79:47-53.

12. Giovannucci E, Rimm EB, Liu Y, Stampfer MJ, Willett WC. A prospective study of tomato products, lycopene, and prostate cancer risk. J. Natl. Cancer I. 2002 94:391-8.

13. Giovannucci E. Tomatoes, tomato-based products, lycopene, and cancer: review of the epidemiologic literature. J. Natl. Cancer I. 1999 91:317-31.

14. Rao AV. Tomatoes, lycopene and human health. Preventing chronic diseases. Caledonian Science Press, Badalona, Spain. 2006.

15. Rao AV, Ray MR, Rao LG. Lycopene. Adv. Food Nutr. Res. 2006 51:99-164.

16. Martin KJ, Gonzàles EA. Metabolic bone disease in chronic kidney disease. JASN 2007 vol 18 ( n. 3) 875- 885

17. Bevilacqua M, Righini V, Vago T, Norbiato G. La vitamina D, biochimica, metabolismo, clinica e farmacologia. Grafiche Moretti, Segrate (MI), 1993 cap. 1.7, $45-47$

18. Quaggiotto P, Tran H, Bhanugopan M. Vitamin D deficiency remains prevalent despite increased laboratory testing in New South Wales, Australia. Singapore Med J 2014 55(5):271-280

19. Cohn W, Thürmann P, Tenter U, Aebischer C, Schierle J, Schalch W. Comparative multiple dose plasma kinetics of lycopene administered in tomato juice, tomato soup or lycopene tablets. European Journal of Nutrition, 200443 (5):304-312

20. Erlinger T P, Selvin E. Prevalence of and Risk Factors for Peripheral Arterial Disease in the United States Circulation. 2004 110: 738-743

21. Kritchevsky S B, Bush AJ, Pahor M, Gross MD. Serum Carotenoids and Markers of Inflammation in Nonsmokers. Am. J. Epidemiol 2000152 (11): 1065-1071

22. Hozawa A, Jacobs D R, Jr Steffes M W, Gross M D, Steffen L M, Lee D H. Relationships of circulating carotenoid concentrations with several markers of inflammation, oxidative stress, and endothelial dysfunction: The Coronary Artery Risk Development in Young Adults (CARDIA)/Young Adult Longitudinal Trends in Antioxidants (YALTA) Study. Clin. Chem. 2007 53:447-455.

23. Clinton SK, Emenhiser C, Schwartz SJ, Bostwick DG, Williams AW, Moore BJ, et al. cis-trans Lycopene isomers, carotenoids, and retinol in the human prostate. Cancer Epidemiol Biomarkers Prev 1996 5:823-33. 
24. Rao A V, Rao L G. Carotenoids and human health. Pharmacological Research 2007 55:207-216

25. Gerster H. The potential role of lycopene for human health. J Am Coll Nutr 1997 16:109-26.

26. Chasse GA, Mak ML, Deretey E, et al. An ab initio computational study on selected lycopene isomers. J Mol Struc (Theochem) 2001 571:27-37.

27. Fuhramn B, Elis A, Aviram M. Hypocholesterolemic effect of lycopene and $\beta$ carotene is related to suppression of cholesterol synthesis and augmentation of LDL receptor activity in macrophage. Biochem Biophys Res Commun 1997 233:658-62.

28. Palozza P, Parrone N, Simone RE, Catalano A. Lycopene in atherosclerosis prevention: an integrated scheme of the potential mechanisms of action from cell culture studies. Arch. Biochem. Biophys. 2010 504:26-33.

29. Young AJ, Lowe GM. Antioxidant and prooxidant properties of carotenoids. Arch. Biochem. Biophys. 2001 385:20-7.

30. Yang Z, Zhang Z, Penniston K L, Binkley N, Tanumihardjo Sherry A. Serum carotenoid concentrations in postmenopausal woman from the United States with and without osteoporosis. Int J Vitamin Nutr Res. 2008 78(3): 105-111

31. Fraser DR. Hyperparathyroidism. Lancet 2009 374: 145-58

32. Ramagopalan SV, Heger A, Berlanga AJ, Maugeri NJ, Lincoln MR, Burrell A. A ChIP-seq defined genome-wide map of vitamin D receptor binding: associations with disease and evolution. Genome Res 2010 20:1352-60. 